Check for updates

Cite this: Chem. Sci., 2019, 10, 9768

๑ All publication charges for this article have been paid for by the Royal Society of Chemistry

Received 19th April 2019

Accepted 29th August 2019

DOI: $10.1039 / c 9 s c 01942 a$

rsc.li/chemical-science

\section{Chronic exposure to complex metal oxide nanoparticles elicits rapid resistance in Shewanella oneidensis MR-1†}

\author{
Stephanie L. Mitchell, (D) ${ }^{a}$ Natalie V. Hudson-Smith, (D) ${ }^{a}$ Meghan S. Cahill, (D) ${ }^{a}$ \\ Benjamin N. Reynolds, ${ }^{b}$ Seth D. Frand, ${ }^{c}$ Curtis M. Green, (D) d Chenyu Wang, (D) d \\ Mimi N. Hang, ${ }^{d}$ Rodrigo Tapia Hernandez, (D) ${ }^{c}$ Robert J. Hamers, (D) d \\ Z. Vivian Feng, (D) ${ }^{c}$ Christy L. Haynes (D) ${ }^{a}$ and Erin E. Carlson (D) *abe
}

Engineered nanoparticles are incorporated into numerous emerging technologies because of their unique physical and chemical properties. Many of these properties facilitate novel interactions, including both intentional and accidental effects on biological systems. Silver-containing particles are widely used as antimicrobial agents and recent evidence indicates that bacteria rapidly become resistant to these nanoparticles. Much less studied is the chronic exposure of bacteria to particles that were not designed to interact with microorganisms. For example, previous work has demonstrated that the lithium intercalated battery cathode nanosheet, nickel manganese cobalt oxide (NMC), is cytotoxic and causes a significant delay in growth of Shewanella oneidensis MR-1 upon acute exposure. Here, we report that S. oneidensis MR-1 rapidly adapts to chronic NMC exposure and is subsequently able to survive in much higher concentrations of these particles, providing the first evidence of permanent bacterial resistance following exposure to nanoparticles that were not intended as antibacterial agents. We also found that when NMC-adapted bacteria were subjected to only the metal ions released from this material, their specific growth rates were higher than when exposed to the nanoparticle. As such, we provide here the first demonstration of bacterial resistance to complex metal oxide nanoparticles with an adaptation mechanism that cannot be fully explained by multi-metal adaptation. Importantly, this adaptation persists even after the organism has been grown in pristine media for multiple generations, indicating that $S$. oneidensis MR-1 has developed permanent resistance to NMC.
Engineered nanomaterials have been impactful in a wide range of emerging technologies and materials (e.g. textiles, ${ }^{1,2}$ electronic screens, ${ }^{3}$ and environmental remediation ${ }^{4}$ ) due to their unique physical and chemical properties. These characteristics also contribute to their antimicrobial properties. Metal and metal oxide nanoparticles such as silver, ${ }^{5,6}$ zinc oxide, $^{7}$ and copper oxide $^{8}$ have been used as antibacterial agents; ${ }^{9}$ the toxicity of these materials is strongly correlated to their size, ${ }^{10,11}$ dissolution, ${ }^{10,12,13}$ and composition, ${ }^{14}$ and the native

${ }^{a}$ Department of Chemistry, University of Minnesota, 207 Pleasant St. SE, Minneapolis, MN 55455, USA. E-mail: carlsone@umn.edu

${ }^{b}$ Department of Biochemistry, Molecular Biology, and Biophysics, University of Minnesota, 321 Church Street SE, Minneapolis, Minnesota 55454, USA

${ }^{c}$ Chemistry Department, Augsburg University, 2211 Riverside Ave, Minneapolis, MN 55454, USA

${ }^{d}$ Department of Chemistry, University of Wisconsin-Madison, 1101 University Avenue, Madison, WI 53706, USA

${ }^{e}$ Department of Medicinal Chemistry, University of Minnesota, 208 Harvard Street SE, Minneapolis, 55454, USA

$\dagger$ Electronic supplementary information (ESI) available: Additional data figures and methods. See DOI: 10.1039/c9sc01942a susceptibility of the organism. Even nanomaterials not intended for antimicrobial applications (zerovalent iron for environmental remediation, ${ }^{15}$ carbon nanotubes, ${ }^{16}$ and CdSe/ZnS quantum $\operatorname{dots}^{17}$ ) can be toxic to bacteria. This toxicity occurs through mechanisms such as reactive oxygen species (ROS) generation, metal dissolution, lipid peroxidation, and mechanical stress. ${ }^{18}$ Another such nanoparticle is lithiated nickel manganese cobalt oxide $\left(\mathrm{Li}_{x} \mathrm{Ni}_{y} \mathrm{Mn}_{z} \mathrm{Co}_{1-y-z} \mathrm{O}_{2}, \mathrm{NMC}\right)$, a battery cathode material that is used at large-scale in electric vehicles. ${ }^{19}$ In January 2015 , there were more than 740000 electric vehicles in operation and it is estimated that by 2020 there will be several million electric vehicles on the road, each containing $\sim 50 \mathrm{~kg}$ of nanoscale cathode materials..$^{14,20}$ Nanoparticles have a large surface-area-to-volume ratio, which is advantageous in materials such as NMC, where lithium is able to efficiently shuttle in and out of the cathode, resulting in increased rate capability. However, some of the properties of NMC that make it an attractive battery cathode are also responsible for its toxicity to bacteria, such as Shewanella oneidensis MR-1. ${ }^{12,14}$ 
S. oneidensis MR-1 is a ubiquitous, Gram-negative, soil-, sediment-, and aquatic-dwelling bacterium that plays a critical role in environmental metal-cycling and is therefore a commonly used model organism in environmental studies. ${ }^{21-23}$ The redox capabilities of $S$. oneidensis MR-1, especially related to the element manganese, indicate that it would be present in environments that may be contaminated by nanoparticle pollutants, such as NMC. ${ }^{24}$ Shewanella has been found to have important roles in metal-cycling in freshwater systems, despite low abundance, and is found in fish making it the prominent cause of fish spoilage. ${ }^{25,26}$ Previous work has shown that modest concentrations of NMC (less than $25 \mathrm{mg} \mathrm{L}^{-1}$ ) impaired the growth of $S$. oneidensis MR-1 to the point that respiration and turbidity were undetectable. ${ }^{12}$ Upon exposure to NMC ( $\left.5 \mathrm{mg} \mathrm{L}^{-1}\right)$, bacterial cultures had extended lag periods $(\sim 20 \mathrm{~h})$, but could ultimately recover to the same level of total respiration as an unexposed population. This led us to develop two hypotheses about the process of bacterial recovery: either (1) the toxicity of NMC is limited both temporally and spatially (i.e. aggregation and sedimentation after a period of time or the accumulation of a biomolecular corona on the nanoparticles), so that the nanoparticles become unavailable to the bacteria and an unaffected population would grow stochastically. The growth delay is due to a smaller starting population, or (2) the delay is due to the time required for a subpopulation of bacteria to adapt to NMC toxicity and recover. Given the serious implications of permanently altering bacterial behaviors, as is most widely understood in relation to antibiotic resistance, we sought to investigate the nature of this phenomenon further.

Toxicity studies are most commonly performed with shortterm, high-dose exposures. These studies enable rapid determination of the acute effects of a substance, but do not reveal the complete extent of their impact. Chronic exposures are critical in ecological toxicity investigations since pollutants such as metals and antibiotics remain in the environment for extended periods. Long-term exposure experiments can reveal deeper complexities of the toxicity and multi-generational impacts. ${ }^{27}$ This is especially true in the study of bacterial exposures, as these organisms replicate very quickly and can share genetic information, which enables them to rapidly adapt to changes in their local environment. It is well-known that repeated exposure to antibiotics, even below the minimum inhibitory concentration (MIC), can stimulate resistance in bacteria or change the diversity of bacterial communities. ${ }^{28,29}$ Therefore, it is important to consider both the environmental relevance and the adaptation capabilities of bacteria when designing toxicity experiments and to perform chronic exposures to evaluate the full extent of organismal response.

In this study, we expose $S$. oneidensis MR-1 to NMC for multiple generations to simulate a chronic, environmental exposure. This resulted in the rapid adaptation of the bacteria to both the nanoparticle and the metal ion controls used to mimic nanoparticle dissolution. We also found that there is a nanoparticle-specific impact based on the growth and morphology of the bacteria that cannot be accounted for by metal dissolution and that would not have been discovered without chronic exposure experiments. Thus, it is clear that even nanoparticles that have been developed exclusively for technological applications, such as NMC, may dramatically affect environmental organisms should they be released accidentally or through improper disposal.

\section{Results \& discussion}

\section{Impact of initial NMC exposure on Shewanella oneidensis MR- 1 (Passage A)}

NMC was synthesized with a specific stoichiometry of $1: 1: 1$ $\mathrm{Ni}: \mathrm{Mn}$ : Co, which is the most toxic NMC studied to date. ${ }^{\mathbf{1 4}}$ TEM images reveal the hexagonal, sheet structures of the NMC nanoparticles with a size distribution across the planar surface of $84 \pm 22 \mathrm{~nm}$ (Fig. S1†). The impact of NMC on S. oneidensis MR-1 was evaluated by optical density (OD) at $600 \mathrm{~nm}$ as a measure of population density. Nanoparticle exposures were performed in minimal media to more closely represent an environmental water system while limiting external influences that may also affect nanoparticle-nanoparticle or nanoparticlebacteria interactions as compared to nutrient rich medias such as LB. NMC suspended in minimal media exhibit a $\zeta$-potential of $-10.3 \pm 0.547 \mathrm{mV}$ indicating that the nanoparticles are not colloidally stable. Dynamic light scattering (DLS) further revealed that NMC begins to aggregate substantially after $24 \mathrm{~h}$

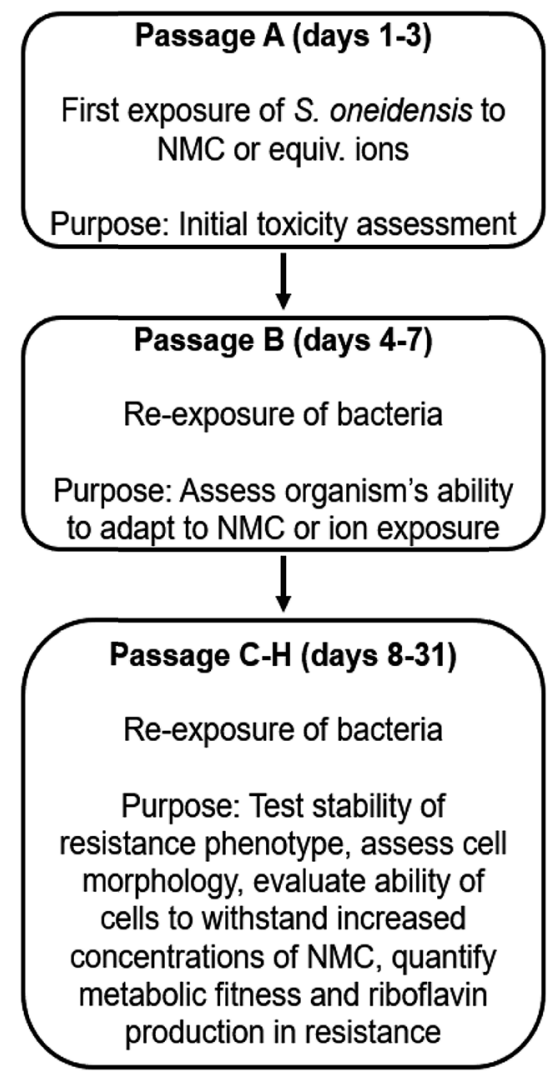

Fig. 1 Schematic of experiments performed in this work to assess $S$. oneidensis MR-1 resistance to NMC. A more detailed schematic is provided in Fig. S3. $\dagger$ 
(Fig. S2†). Initially, bacteria were exposed to NMC immediately upon inoculation of the culture (time $0 \mathrm{~h}$ ), yielding growth curves similar to those previously published (Fig. 2A; brief experimental scheme provided in Fig. 1, detailed experimental scheme provided in Fig. S3†). ${ }^{12}$ Cultures were exposed to either $5 \mathrm{mg} \mathrm{L}{ }^{-1}$ or $25 \mathrm{mg} \mathrm{L}^{-1} \mathrm{NMC}$, concentrations that previous research indicate are representative of recoverable nanoparticle pressure $\left(5 \mathrm{mg} \mathrm{L}^{-1}\right)$ and irrecoverable nanoparticle toxicity $\left(25 \mathrm{mg} \mathrm{L}^{-1}\right) \cdot{ }^{12,14}$ Immediate exposure to $25 \mathrm{mg} \mathrm{L}^{-1}$ NMC rapidly killed the organisms, making it difficult to assess the potential long-term effects of chronic exposure. Instead, we found that allowing the culture to grow before addition of NMC (10 h) enabled us to perform chronic exposures and to observe more subtle effects than cell death. The delay in NMC addition could also facilitate examination of a greater range of NMC concentrations since the cultures are less sensitive to $25 \mathrm{mg} \mathrm{\textrm {L } ^ { - 1 }} \mathrm{NMC}$ (Fig. 2B). This change in response is likely due to the inoculum effect, a phenomenon often used to describe the impact of bacterial density on MIC values, where a higher bacterial density requires a higher concentration of antibiotic to kill the bacteria. Although traditionally used to discuss changes in antibiotic toxicity, it could also explain the observed changes in nanoparticle toxicitiy. ${ }^{30}$ More specifically, this effect could indicate that NMC has different mechanisms of toxicity at different growth stages. ${ }^{31}$ Interestingly, previous work demonstrated that immediate exposure caused an increase in the lag phase; however, we found that delayed exposure $(10 \mathrm{~h}$, $25 \mathrm{mg} \mathrm{L}^{-1} \mathrm{NMC}$ ) affected the maximal population density achieved in the stationary phase by at least half in comparison to untreated cultures. Studies utilizing similar delayed exposure protocols have also yielded a decrease in the stationary phase when $S$. oneidensis MR-1 was exposed to chromium(vi) and $E$. coli to silver nanoparticles (AgNPs). ${ }^{31,32}$

Previous work has shown that NMC toxicity to $S$. oneidensis MR-1 is related to its dissolution and release of ions, particularity nickel and cobalt, into the growth media. ${ }^{\mathbf{1 2}}$ Although some of these metals are micronutrients, metal homeostasis of the organism is disturbed at higher concentrations of nickel and copper, which could cause oxidative stress, the replacement of the native metal cofactor of some proteins, or the binding of
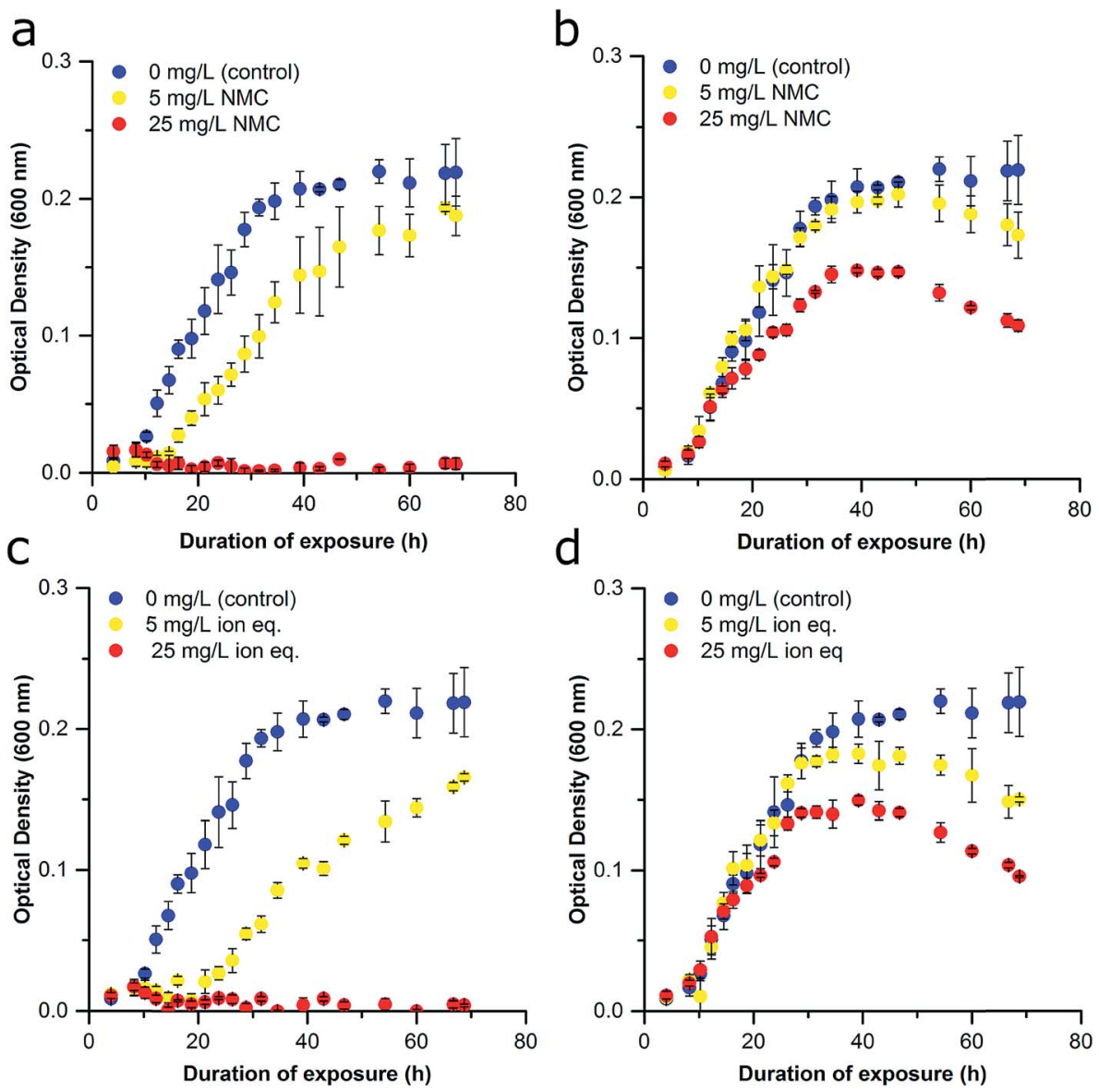

Fig. 2 Effect of delayed NMC and ion exposure on growth inhibition of S. oneidensis MR-1 (Passage A). (a) Bacterial exposure at the time of inoculation to no NMC (blue), $5 \mathrm{mg} \mathrm{L}^{-1} \mathrm{NMC}$ (yellow), and $25 \mathrm{mg} \mathrm{L}^{-1} \mathrm{NMC}$ (red). (b) Bacterial exposure $10 \mathrm{~h}$ after the inoculation to no NMC (blue), $5 \mathrm{mg} \mathrm{L}^{-1} \mathrm{NMC}$ (yellow), and $25 \mathrm{mg} \mathrm{L}^{-1} \mathrm{NMC}$ (red). (c) Bacterial exposure to constitutive ions of NMC at time of inoculation: no NMC ions (blue), ions of $5 \mathrm{mg} \mathrm{L}^{-1}$ eq. of NMC (yellow), and ions of $25 \mathrm{mg} \mathrm{L}^{-1}$ eq. of NMC (red). (d) Bacterial exposure to constitutive ions of NMC $10 \mathrm{~h}$ after inoculation: no NMC ions (blue), ions of $5 \mathrm{mg} \mathrm{L}^{-1}$ eq. of NMC (yellow), and ions of $25 \mathrm{mg} \mathrm{L}^{-1}$ eq. of NMC (red). Error bars represent the standard deviation of three replicates. 
metals with critical functional groups on proteins or nucleic acids. ${ }^{18,33-35}$ Delayed exposures were also performed with solutions of $\mathrm{LiOH}, \mathrm{NiCl}_{2}, \mathrm{MnSO}_{4}, \mathrm{CoCl}_{2}$ to recapitulate the known metal ion concentrations after $96 \mathrm{~h}$ of NMC dissolution based on ICP-OES measurements (Fig. S4 $\dagger$ ). These too revealed the dose-dependent nature of NMC-derived ion toxicity and strengthened the postulation that dissolved ions are responsible for a large proportion of NMC toxicity to $S$. oneidensis MR-1 (Fig. 2C and D). ${ }^{\mathbf{1 2} 14}$ Comparison of the growth curves of bacteria exposed to NMC or the ion equivalent in Passage A reveal only subtle differences (e.g., lag time $(\lambda)$, specific growth rate $(\mu)$, maximum OD; Fig. 2B, D and S5 $\dagger$ ).

\section{Repetitive exposure to NMC (Passage B)}

To examine the ability of this organism to activate processes required for survival under toxic conditions, we performed serial nanoparticle exposures and monitored bacterial response (Fig. 1). After an initial $72 \mathrm{~h}$ of growth (preventing cultures from reaching declining stage), cultures exposed to 0,5 , or $25 \mathrm{mg} \mathrm{L}^{-1}$ NMC (Passage A) were each diluted to the same OD $(\sim 0.1$; half of the starting bacterial density used in Passage A) to achieve similar population densities and further diluted $1: 10(\mathrm{v} / \mathrm{v})$ into fresh media and lactate for Passage B. Freshly inoculated cultures generated from Passage A bacteria were immediately exposed $(0$ h) to either $5 \mathrm{mg} \mathrm{L}^{-1}, 25 \mathrm{mg} \mathrm{L}^{-1} \mathrm{NMC}$ or left untreated for $96 \mathrm{~h}$. Unperturbed $S$. oneidensis had a doubling time of $\sim 6$ hours in minimal media. Thus, there are $\sim 16$ generations of replication per $96 \mathrm{~h}$ passage. Cultures reseeded into fresh media without nanoparticles $\left(0 \mathrm{mg} \mathrm{L}^{-1}\right)$ were able to reach exponential phase growth in the order of apparent fitness; the control cultures had the shortest lag time, followed by the cultures previously exposed to $5 \mathrm{mg} \mathrm{L}^{-1} \mathrm{NMC}$, and then those previously exposed to $25 \mathrm{mg} \mathrm{L}^{-1}$ NMC (lag time doubled in comparison to control). The specific growth rate for cultures exposed to $25 \mathrm{mg} \mathrm{L}^{-1} \mathrm{NMC}$ in Passage A was less than half that of the control samples (Fig. 3A and $55 \dagger$ ). When Passage A cultures were reseeded and exposed to $5 \mathrm{mg} \mathrm{\textrm {L } ^ { - 1 }} \mathrm{NMC}$, only the cultures that had previously been exposed to $5 \mathrm{mg} \mathrm{L^{-1 }}$ or $25 \mathrm{mg} \mathrm{L}^{-1} \mathrm{NMC}$ were able to grow (Fig. 3B). These results indicate that due to the initial exposure, $S$. oneidensis MR-1 has adapted and is able to replicate under conditions that were previously toxic.

Additionally, organisms that previously experienced the highest concentrations of NMC appeared to be the most robust

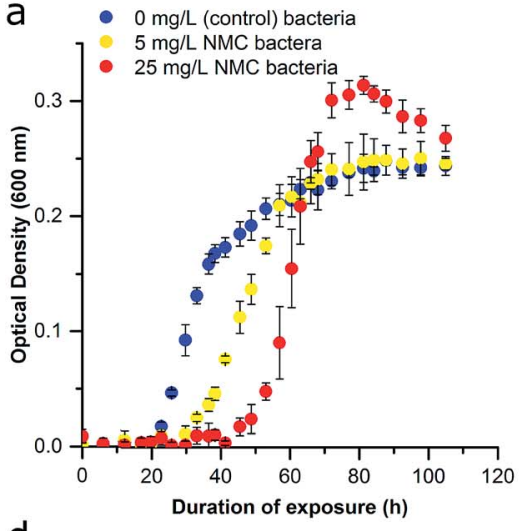

d

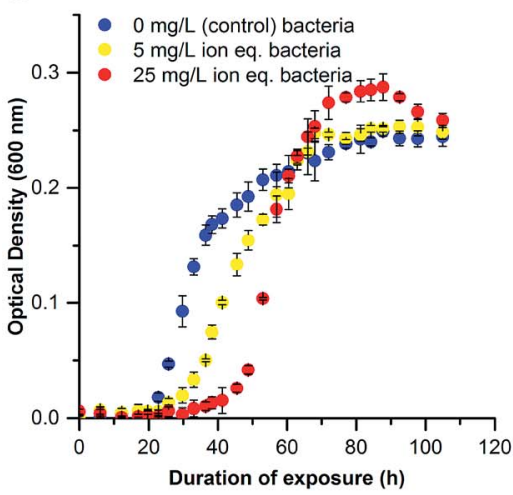

b

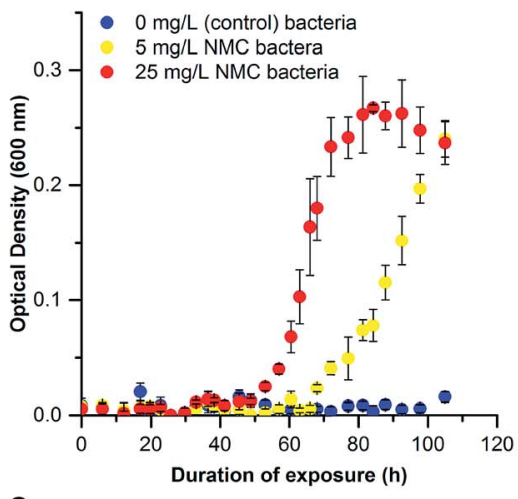

$\mathrm{e}$

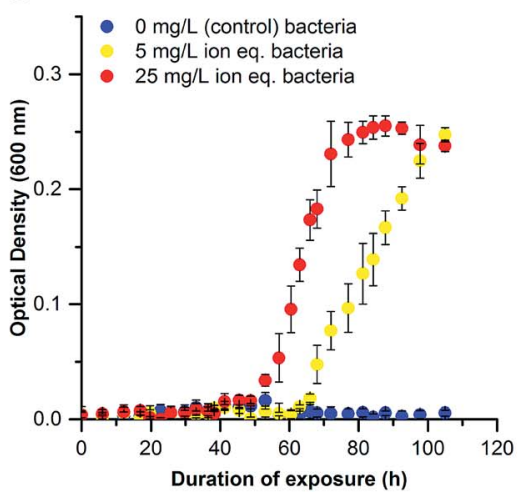

C

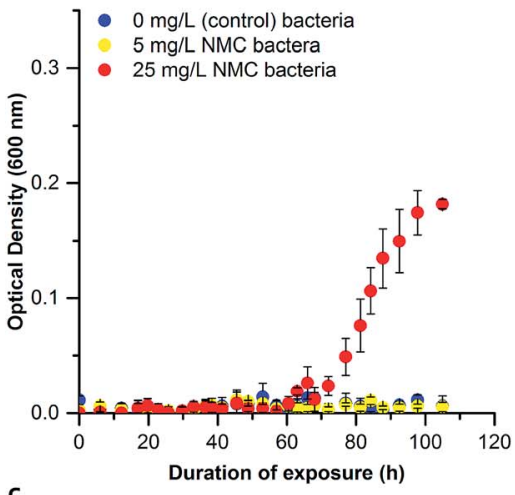

f

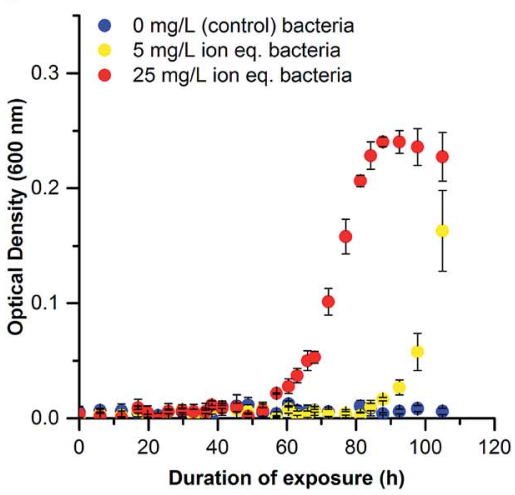

Fig. 3 Effect of repetitive NMC and ion exposure on growth inhibition of S. oneidensis MR-1 (Passage B). (a-c) Bacteria from Passage A that were previously exposed to control conditions in Passage $A$ are represented in blue, bacteria that were exposed to $5 \mathrm{mg} \mathrm{L}^{-1} \mathrm{NMC}$ in Passage $A$ are represented in yellow, and bacteria exposed to $25 \mathrm{mg} \mathrm{L}^{-1} \mathrm{NMC}$ in Passage A are represented in red. (a) Bacteria from Passage A cultured in control conditions, (b) bacteria from Passage A cultured in $5 \mathrm{mg} \mathrm{L}^{-1} \mathrm{NMC}$, (c) bacteria from Passage A cultured in $25 \mathrm{mg} \mathrm{L}^{-1} \mathrm{NMC}$. (d-f) Bacteria from Passage $A$ that were previously exposed to control conditions in Passage $A$ are represented in blue, bacteria that were exposed to 5 mg $L^{-1}$ NMC ion eq. in Passage A are represented in yellow, and bacteria exposed to $25 \mathrm{mg} \mathrm{L}^{-1} \mathrm{NMC}$ ion eq. in Passage $A$ are represented in red. (d) Bacteria from Passage A cultured in control conditions, (e) bacteria from Passage A cultured in $5 \mathrm{mg} \mathrm{L}^{-1} \mathrm{NMC}$ ion eq., (f) bacteria from Passage $\mathrm{A}$ cultured in $25 \mathrm{mg} \mathrm{L}^{-1} \mathrm{NMC}$ ion eq. Error bars represent the standard deviation of three replicates. 
in subsequent exposures. For example, when the Passage A cultures were cultivated in media containing $25 \mathrm{mg} \mathrm{L}^{-1} \mathrm{NMC}$ for Passage $\mathrm{B}$, only bacteria that had previously been subjected to $25 \mathrm{mg} \mathrm{L}^{-1}$ NMC could survive (Fig. 3C). This adaptation is significant as the bacteria are capable of growth in NMC concentrations that were lethal to unexposed bacteria (Fig. 2A). Adaptation was rapid and occurred in around 6 generations (with an estimated doubling time of $11.5 \mathrm{~h}$ of bacteria exposed to $25 \mathrm{mg} \mathrm{L}^{-1}$ NMC during Passage A exposure). This is considered rapid compared to other work, which showed that E. coli became resistant to AgNP exposure in 100 generations, B. subtilis adapted to a concentration of nanosilver(I) oxide that was $1.5 \times$ greater than the lethal dose in 13 days, while others indicated an increase in MIC after only a few sub-culturing periods of $24 \mathrm{~h}^{.36-38}$ These experiments were also performed by reseeding cultures that had been exposed to ions in Passage A into fresh, ion-containing media, with concentrations representing the dissolution of $5 \mathrm{mg} \mathrm{L}^{-1}$ and $25 \mathrm{mg} \mathrm{L}^{-1} \mathrm{NMC}$ after $96 \mathrm{~h}$ (Fig. 3D-F). The trend in these growth curves is similar to that of the NMC exposures but indicates that the ions may be less toxic than the nanoparticle when comparing adapted cultures (compare Fig. 3C, F and S5†). ${ }^{\mathbf{1 4}}$

\section{Adaptation characterization (Passage C, D, and beyond)}

The adaptation phenotype was characterized by growth studies in addition to analysis of population respiration. For Passage C, the adaptation to NMC toxicity and constitutive ion toxicity were compared. The untreated populations and those that had been exposed to $25 \mathrm{mg} \mathrm{L}^{-1} \mathrm{NMC}$ and the ion equivalent of $25 \mathrm{mg} \mathrm{L}^{-1}$ for two passages were diluted and re-exposed to $25 \mathrm{mg} \mathrm{L}^{-1}$ $\mathrm{NMC}$, the $25 \mathrm{mg} \mathrm{L}^{-1}$ ion equivalent, or control media. The concentration of $25 \mathrm{mg} \mathrm{L}{ }^{-1}$ was selected because it represents a lethal dose of NMC and its ion equivalent to sensitive $S$. oneidensis MR-1. Optical density studies reveal that when untreated cultures were reseeded into fresh, NMC-, and ioncontaining media, the population of $S$. oneidensis MR-1 was only able to replicate in clean media as expected (Fig. 4A). Again, we found that ion- and NMC-adapted cultures had shorter lag periods in control conditions than when the same organisms were grown in the presence of NMC or ions (Fig. 4B, C and S5 $\dagger$ ). Interestingly, when the population adapted to $25 \mathrm{mg} \mathrm{L}^{-1} \mathrm{NMC}$ was exposed to the equivalent metal ions, the specific growth rate was higher than the culture that was instead exposed to NMC (Fig. 4B and S5†). This was also seen when the population adapted to metal ions (equivalent to $25 \mathrm{mg} \mathrm{\textrm {L } ^ { - 1 }} \mathrm{NMC}$ ) was exposed to ions or NMC (Fig. 4C). The dissolution of metal ions has been proposed to be the major mechanism of NMC antibacterial activity to $S$. oneidensis $\mathrm{MR}-1$, and comparison of NMCand ion-adapted cultures confirm this. However, in both treatments of adapted cultures, exposure to NMC presented a greater challenge to bacterial growth than the constitutive ions based on specific growth rate differences, indicating that adaptation to nanoparticles is more complex than adaptation to multiple metal ions alone (Fig. S5 $\dagger$ ). ${ }^{\mathbf{1 4 , 3 9 , 4 0}}$

The distinction between the toxicity of the nanoparticle or its ions was difficult to discern during the first exposure in Passage A, but comparison of the adapted cultures to unadapted organisms made these differences more apparent. We had anticipated that exposure to the entirety of NMC dissolution products (the metal ion control) immediately after culture inoculation would be more toxic than NMC due to the heavy front-loading of the free ions on an unestablished, low-density culture. Yet, there is more available lactate for metal chelation, based on previous modeling work, which in turn could make the toxic metal ions less bioavailable. ${ }^{\mathbf{1 2 , 1 4 , 3 4}}$ As these two effects cannot be easily reconciled, this is most likely an indication of unique particle-specific toxicity, such as ROS generation. ${ }^{\mathbf{1 4 , 4 1}}$

We tested the consistency of this trend by performing the same experiment in Passage E with cultures that had been continuously cultured with either $25 \mathrm{mg} \mathrm{L}^{-1} \mathrm{NMC}, 25 \mathrm{mg} \mathrm{L}^{-1}$ ion equivalent, or in control media for the previous four
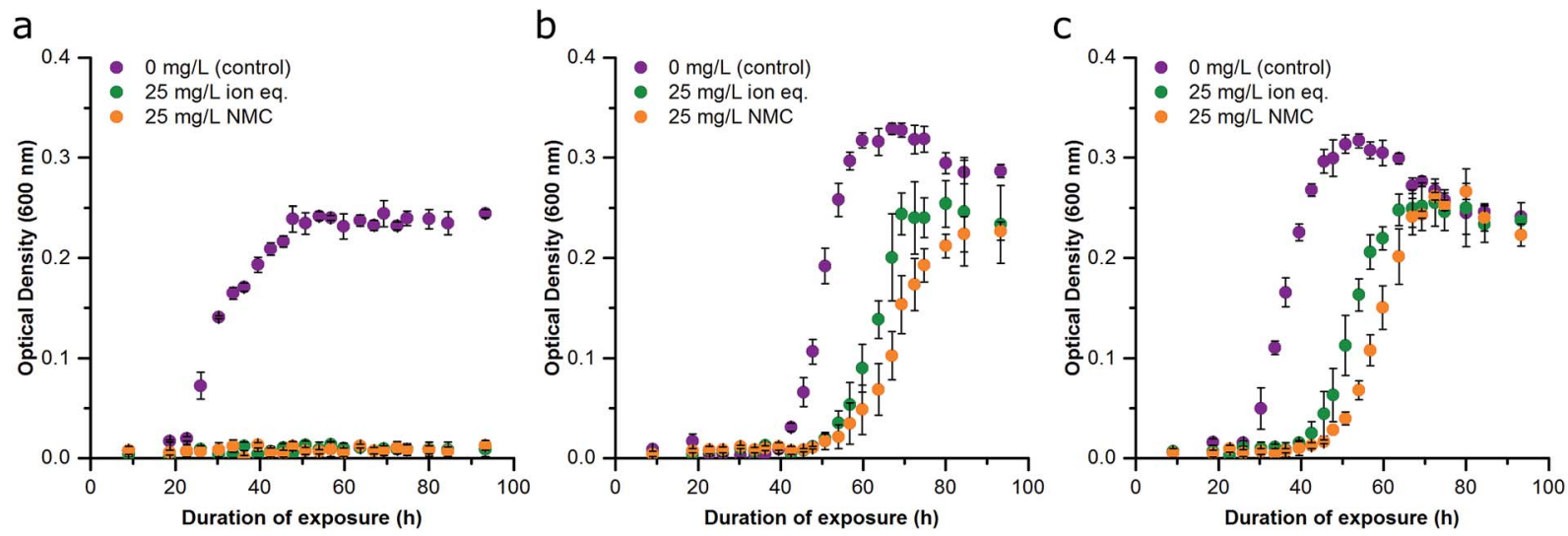

Fig. 4 Effect of repetitive NMC and ion exposure on growth inhibition of S. oneidensis MR-1 (Passage C). (a) Bacteria cultured for two passages in pristine media exposed to no NMC (purple), $25 \mathrm{mg} \mathrm{L}^{-1} \mathrm{NMC}$ ion eq. (green), and $25 \mathrm{mg} \mathrm{L}^{-1} \mathrm{NMC}$ (orange). (b) Bacteria cultured for two passages with $25 \mathrm{mg} \mathrm{L}^{-1} \mathrm{NMC}$, which was then exposed to no NMC (purple), $25 \mathrm{mg} \mathrm{L}^{-1} \mathrm{NMC}$ ion eq. (green), and $25 \mathrm{mg} \mathrm{L}^{-1} \mathrm{NMC}$ (orange). (c) Bacteria cultured for two passages with $25 \mathrm{mg} \mathrm{L}^{-1} \mathrm{NMC}$ ion eq., which was then exposed to no NMC (purple), $25 \mathrm{mg} \mathrm{L}^{-1} \mathrm{NMC}$ ion eq. (green), and $25 \mathrm{mg} \mathrm{L}^{-1} \mathrm{NMC}$ (orange). Error bars represent the standard deviation of three replicates. 
passages. The same trend was observed in optical density growth curves (Fig. S6 $\dagger$ ). In this passage, turbidity measurements were supplemented with respirometry measurements (cumulative $\mathrm{O}_{2}$ consumption) of the cultures, which also demonstrated the same trend in toxicity and adaptation (Fig. 5). Analysis of the first derivative of these curves reveals differences in the time required to reach peak oxygen consumption (Fig. S7 $\dagger$ ). The organisms that were unexposed in Passage E reached peak oxygen consumption first, followed by the bacteria that had been exposed to ions, and finally, cultures that had previously been subjected to NMC took the longest to reach their peak respiration rate. These data also indicate that exposed organisms are respiring less overall than control bacteria in pristine media.

We next sought to determine if the organismal adaptation(s) were stable, which would imply a genome-level alteration was facilitating resistance. First, cells were removed from NMC or ion pressure and cultured in fresh media with no treatment starting with Passage $\mathrm{C}$ for subsequent passages in an attempt to rescue the sensitive phenotype. After each passage was grown under normal conditions (unexposed), the adapted cultures were again exposed to $25 \mathrm{mg} \mathrm{L}^{-1} \mathrm{NMC}$ or the ion equivalent. These cultures were compared to the control, NMC-, and ionadapted cultures that had been repeatedly exposed throughout all passages. After five additional passages (estimated to be 67 generations) with no treatment, the NMC- and ion-adapted cultures maintained their adaptation phenotype, indicating that this adaption is stable in the absence of NMC or metal ion pressure (Fig. 6A and B). This likely indicates a chromosomal mutation that does not perturb organism fitness, which will be assessed in future studies. ${ }^{42}$ This is also implied by the exposed organism's ability to achieve similar specific growth rates and lag times in comparison to control (Passage D and beyond; Fig. S5 and S8†). Permanent perturbations to bacterial characteristics have the potential to change the behavior of a microbial community and therefore have significant and long-term impact on ecosystems health and stability. Microbes perform a wide range of functions in the environment such as nutrient cycling, which make them excellent indicators of environmental health. ${ }^{43,44}$

To demonstrate that the adapted organism could survive under increasing pressure, bacteria that had been exposed to $25 \mathrm{mg} \mathrm{L}^{-1}$ NMC (Passage B) were reseeded into higher concentrations of NMC, revealing that the organism could now grow in $75 \mathrm{mg} \mathrm{L}^{-1} \mathrm{NMC}(3 \times$ the previous exposure; Fig. $6 \mathrm{C})$. We observed an increase in the lag phase at higher NMC concentrations and hypothesize that this either represents the activation of additional molecular defenses (e.g. efflux pumps, oxidative stress protection), increased preliminary killing that decreases the initial cell density, or the development of new mutations. An increase in lag phase has been associated with adaptation to new environments, as well as to toxic substances such as antibiotics. Although little is known about bacterial lag phase, it is likely that an increased lag phase enables increased tolerance to antibiotics to promote the further evolution of antibiotic resistance..$^{45}$ Other work has also shown an increase in lag phase when bacteria where exposed to metal oxide
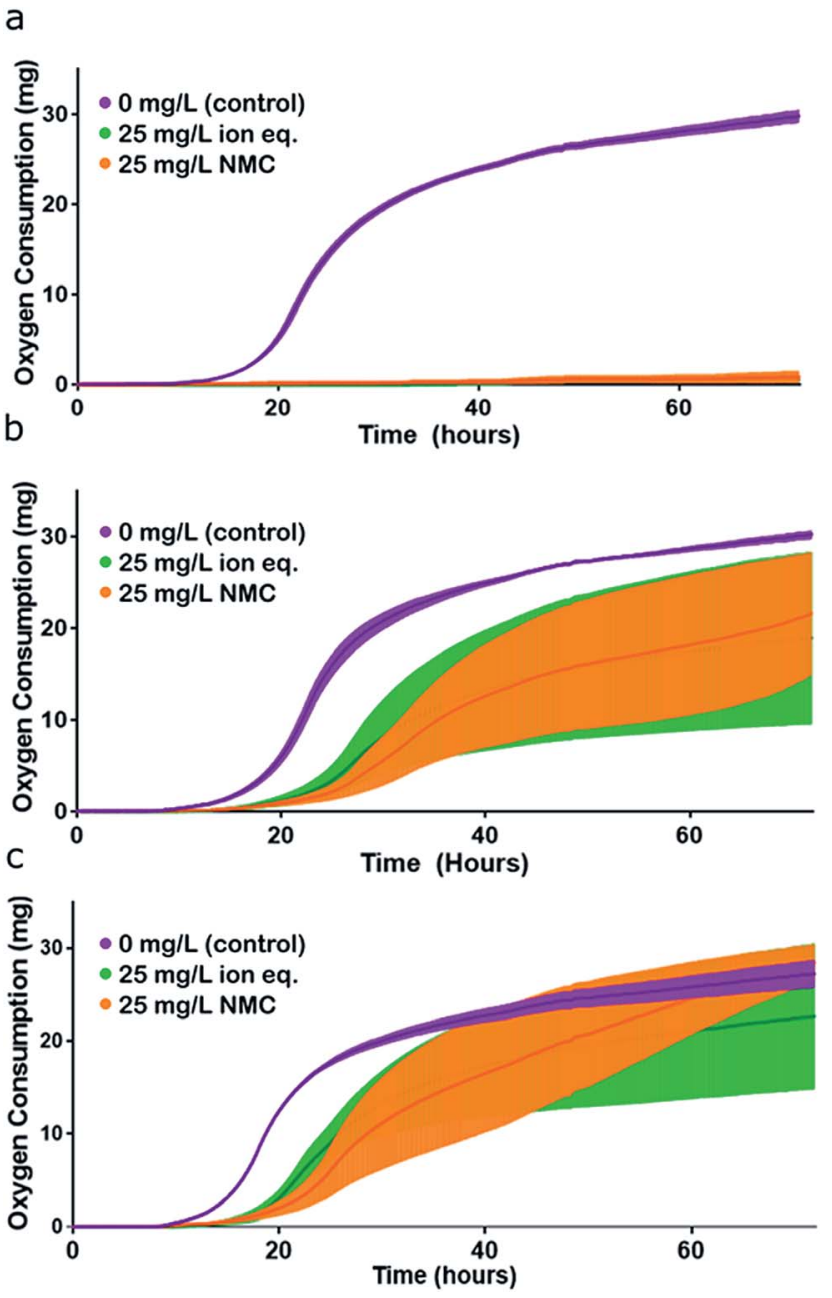

Fig. 5 Assessment of organismal fitness by measurement of oxygen consumption. (a) Respirometry curves of $\mathrm{S}$. oneidensis MR-1 control (unadapted) cultures exposed to control conditions (purple), $25 \mathrm{mg} \mathrm{L}^{-1}$ NMC (orange), and $25 \mathrm{mg} \mathrm{L}^{-1} \mathrm{NMC}$ ion eq. (green) in Passage E. (b) Respirometry curves of NMC-adapted cultures exposed to control conditions (purple), $25 \mathrm{mg} \mathrm{L}^{-1} \mathrm{NMC}$ (orange), and $25 \mathrm{mg} \mathrm{L}^{-1} \mathrm{NMC}$ ion eq. (green) in Passage E. (c) Respirometry curves of ion-adapted cultures exposed to control conditions (purple), $25 \mathrm{mg} \mathrm{L}^{-1} \mathrm{NMC}$ (orange), and $25 \mathrm{mg} \mathrm{L}^{-1} \mathrm{NMC}$ ion eq. (green) in Passage E. Error bars represent the standard deviation of replicates. Representation of this figure without standard deviations is located in Fig. S7.†

nanoparticles. ${ }^{46,47}$ In Passage $\mathrm{D}$, the population that grew in $50 \mathrm{mg} \mathrm{L}{ }^{-1} \mathrm{NMC}$ was successfully cultured in $100 \mathrm{mg} \mathrm{L}^{-1} \mathrm{NMC}$ (Fig. S9†). This confirms that the adaption is robust and flexible as the $S$. oneidensis MR-1 is capable of replication in a concentration of NMC that is 20 times that which was found to kill unexposed bacteria.

To quantify the increased tolerance of the organism to NMC, we obtained the MIC values for lithium, nickel, manganese, and cobalt ions on both the adapted and control populations in Passage D, as the ability to withstand increased concentrations of an antibacterial substance is one of the hallmarks of resistance. ${ }^{38,48}$ The adapted bacteria were capable of surviving in concentrations of nickel and cobalt metal ions at least three times higher than the unadapted cultures (Fig. S10†). No 
a

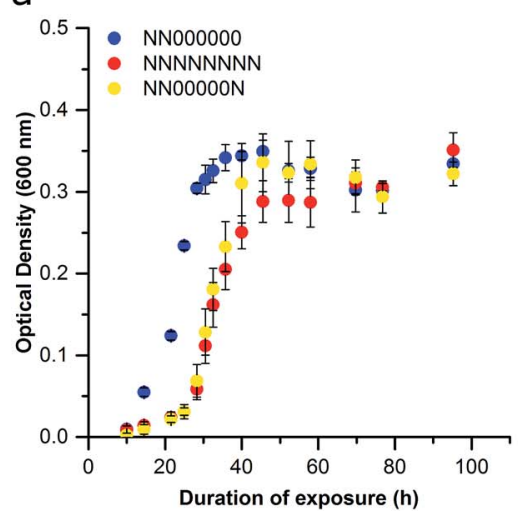

b

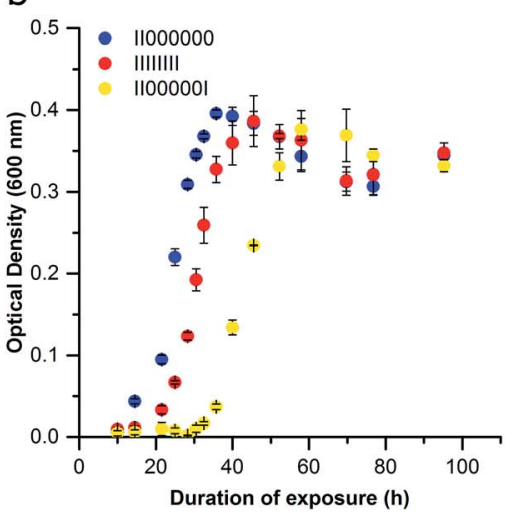

C

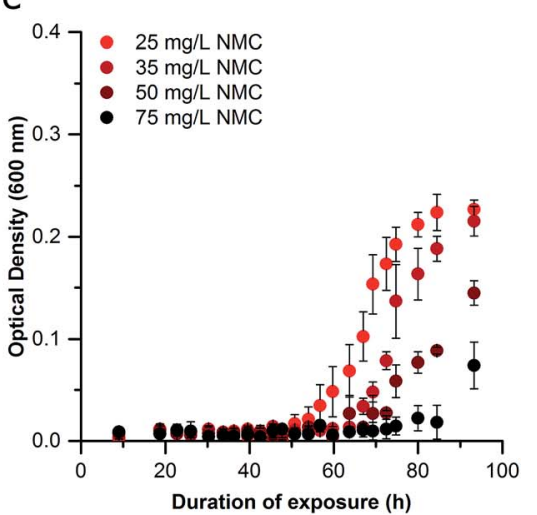

Fig. 6 Examination of the stability of the bacterial adaptation following a period of non-exposure (Passage H). (a) Bacteria cultured for two passages in $25 \mathrm{mg} \mathrm{L}^{-1} \mathrm{NMC}$ were then grown for 5 passages without exposure, and then a final passage exposed to $25 \mathrm{mg} \mathrm{L}^{-1} \mathrm{NMC}$ ( NN00000N; yellow) or no NMC (NN000000; blue) and compared to continually exposed cultures (NNNNNNNN; red). (b) Bacteria cultured for two passages in the ion eq. of $25 \mathrm{mg} \mathrm{L}^{-1} \mathrm{NMC}$ were then for grown for 5 passages without exposure, and then a final passage exposed to the ion eq. of 25 mg L ${ }^{-1}$ NMC (II00000I; yellow) or no NMC (II000000; blue) and compared to continually exposed cultures (IIIIIII; red). (c) Bacteria cultured for two passages in $25 \mathrm{mg} \mathrm{L}^{-1}$ NMC were then exposed to increasing concentrations of NMC (Passage C). Error bars represent the standard deviation of three replicates.

changes in the MIC values for dissolved lithium and manganese were observed, likely because the concentrations required to cause adaptation pressure are not achieved through NMC dissolution.

The final confirmation of resistance is to eliminate the possibility that there was a subpopulation of persistent microbes in the original culture. Because we see active replication of the adapted populations and those exposed to increasing concentrations of NMC, it is likely that the bacteria are not persistent. As further confirmation, we performed a minimum duration for killing 99\% (MDK99) assay on the unadapted $S$. oneidensis MR-1, which provides an indication of the mechanism of bacterial adaptation [colony forming units (CFUs) per mL]. This assay revealed that there is no persistent or resistant subpopulation in the unadapted population (Fig. S11†). Additionally, unadapted S. oneidensis exposed to $25 \mathrm{mg} \mathrm{L}^{-1} \mathrm{NMC}$, which appears to cause complete cell death, were reseeded into nutrient-rich lysogeny broth (LB). There was no growth in this subculture, which indicated that there are no viable bacteria after exposure to this dose of NMC (data not shown). In combination, these three observations, adaptation stability, increased MIC values, and the lack of persistent population, indicate that $S$. oneidensis MR-1 has developed stable resistance to NMC, permanently altering its biochemical and morphological characteristics (vide infra). ${ }^{38,49}$

\section{Initial mechanistic investigation of resistance: electron microscopy}

We next examined the morphology of cultures that were resistant to the ions and NMC nanoparticles in comparison to the passaged control with scanning electron microscopy (SEM; Passage D; Fig. 7 and S12†). The bacteria that had adapted to NMC exposure were filamented compared to the passaged control, showing a massive range of lengths up to $60 \mu \mathrm{m}$ (median length $8.9 \mu \mathrm{m}$, passaged control $3.1 \mu \mathrm{m}$ ). The NMC- adapted bacteria (median $8.9 \mu \mathrm{m}$ ) were also substantially longer than ion-adapted bacteria (median $3.4 \mu \mathrm{m}$ ), indicating there was additional burden on the nanoparticle-exposed population. The control bacteria that had been cultured for four consecutive passages were compared to a fresh culture that had never been subcultured, confirming minimal filamentation stress due to subculturing alone (median 2.3 versus $3.1 \mu \mathrm{m}$ ).

Filamentation is a known mechanism of bacterial response and adaptive processes as it occurs when bacteria experience stress or environmental change, and is related to some resistance mechanisms..$^{50,51}$ This could give bacteria an evolutionary advantage in combatting stress and preventing further damage. The filamentation of S. oneidensis MR-1 under exposure conditions indicates that this is a part of its adaptation mechanism to protect from NMC toxicity and has been previously observed after chromium(Iv) and cadmium selenide quantum dot exposure in S. oneidensis MR-1. ${ }^{52,53}$ Interestingly, when the ionadapted population is grown in pristine media, it still shows a small increase in filamentation compared to the control, indicating that this phenotype persists even after the stress has been removed. When the NMC-adapted population is grown under control conditions, it shows a significant decrease in filamentation (now similar to ion-adapted), indicating a decrease in stress while the adaptation-phenotype persists in OD studies (Fig. 6A and 7).

Extensive bacterial filamentation may have profound impacts on the environment due to the critical role and pervasive nature of $S$. oneidensis MR-1. This stress response could influence the activity of $S$. oneidensis MR-1 in the environment due to changes in metabolic activity and metal and small molecule turnover, but could also make it more difficult for predators to consume. Finally, if filamentation is a global response to nanoparticle adaption, this could also enable pathogens to become more resistant to antibiotics as filamentation is a known antibiotic resistance mechanism. ${ }^{\mathbf{5 0 , 5 1}}$ 
Bacteria from Passage $\mathrm{C}$ were also analyzed by transmission electron microscopy (TEM) to determine if cell envelope structures were altered during the adaptation process to either ions or particles (Fig. S13†). The envelope of bacteria and its components (e.g., lipopolysaccharides) are the first interface of the organism to interact with the nanoparticle and its ions. ${ }^{\mathbf{5 4 5 5}}$ Previous work has shown that there is no internalization of NMC by $S$. oneidensis MR-1 and no significant membrane association of NMC after 30 min of exposure. ${ }^{12,14}$ The negative charge of the nanoparticles makes it less likely to interact with the negatively charged bacterial envelope (Fig. S2 $\dagger$ ). ${ }^{56}$ However, after prolonged exposure and a clear adaptation phenotype, it is important to evaluate if the stress of NMC has caused alterations in the membrane and cell wall structures. ${ }^{57}$ Untreated $S$. oneidensis MR1 had a smooth bacterial membrane as reported previously. ${ }^{\mathbf{1 2 , 1 4}}$ Cultures adapted to $25 \mathrm{mg} \mathrm{L}{ }^{-1} \mathrm{NMC}$ and $25 \mathrm{mg} \mathrm{L}^{-1} \mathrm{NMC}$ metal ions show filamentation as seen in SEM images, but no significant morphological differences in the cell envelope.

\section{Initial mechanistic investigation of resistance: secreted biomolecules}

S. oneidensis MR-1 is well known for its ability to reduce a variety of extracellular substances and metals via secretion of riboflavin, an electron shuttle that is transported through the Mtr pathway, which is a collection of membrane-embedded cytochrome proteins. ${ }^{\mathbf{5 8 , 5 9}}$ The Mtr pathway of $S$. oneidensis MR-1 has been linked to the reduction of metals and metal oxides, including manganese and cobalt under anaerobic conditions. ${ }^{\mathbf{6 0 , 6 1}}$ Furthermore, riboflavin has been shown to increase in the supernatant of a culture over time, as well as after exposure to $\mathrm{TiO}_{2}$ nanoparticles. ${ }^{\mathbf{5 8 , 6 2}}$ The modification of metal oxidation states has been identified as a mechanism of bacterial resistance to toxic metals. ${ }^{63}$ Due to the change in behavior of $S$. oneidensis MR-1 during repeated exposures to metals, it was considered likely that the activity of this pathway and the secreted concentration of riboflavin may increase. As such, throughout Passages A-E the supernatants were collected for riboflavin analysis by liquid chromatography-mass spectrometry (LC-MS). We observed an increase in relative riboflavin concentrations upon treatment with NMC or its ions that persisted across multiple passages, correlating with the stability of the resistance phenotype (Fig. 8 and $\mathrm{S} 14 \dagger$ ). Populations exposed to $25 \mathrm{mg} \mathrm{\textrm {L } ^ { - 1 }}$ of NMC during the first passage show a slight decrease in relative riboflavin concentrations when normalized to optical density. Yet, bacteria exposed to only $5 \mathrm{mg} \mathrm{\textrm {L } ^ { - 1 }}$ of NMC or the ion equivalents secreted more riboflavin than the control. This contrast could be due to the fitness of the populations during the initial exposure (Passage A) and indicate that more resources are allocated to other survival mechanism instead of riboflavin secretion after exposure to $25 \mathrm{mg} \mathrm{L}^{-1} \mathrm{NMC}$. During subsequent passages (B-E), the relative concentrations of riboflavin are significantly different from the control, but do
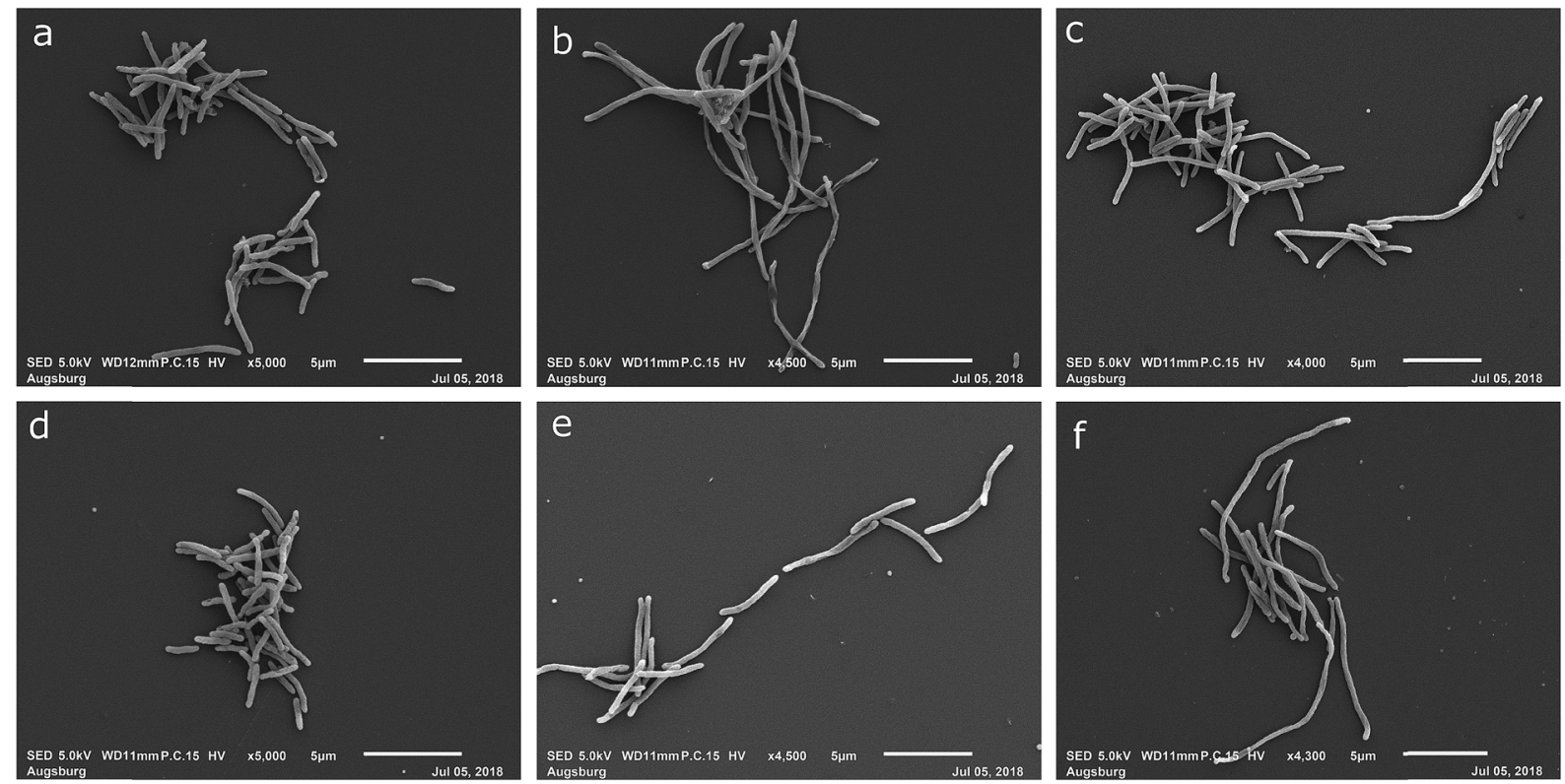

\begin{tabular}{ccccccc} 
& Control & $\begin{array}{c}\text { Passaged } \\
\text { Control }\end{array}$ & $\begin{array}{c}\text { NMC- } \\
\text { Adapted }\end{array}$ & $\begin{array}{c}\text { NMC } \\
\text { Rescue }\end{array}$ & $\begin{array}{c}\text { Ion- } \\
\text { Adapted }\end{array}$ & $\begin{array}{c}\text { Ion } \\
\text { Rescue }\end{array}$ \\
\cline { 2 - 7 } Mean $(\mu \mathrm{m})$ & $2.3 \pm 0.5$ & $3.2 \pm 0.9$ & $10.8 \pm 9.5$ & $4.5 \pm 1.9$ & $3.9 \pm 2.0$ & $5.4 \pm 4.0$ \\
Median $(\mu \mathrm{m})$ & 2.3 & 3.1 & 8.9 & 4.1 & 3.4 & 4.4 \\
N & 354 & 253 & 60 & 366 & 340 & 306
\end{tabular}

Fig. 7 Morphology assessment. Scanning electron micrographs of S. oneidensis MR-1 from Passage D exposed to (a) no nanoparticle or ions over 4 passages, (b) $25 \mathrm{mg} \mathrm{L}^{-1} \mathrm{NMC}$ over 4 passages (c) $25 \mathrm{mg} \mathrm{L}^{-1} \mathrm{NMC}$ ion eq. over 4 passages (d) no nanoparticle or ions for one passage, (e) $25 \mathrm{mg} \mathrm{L}^{-1} \mathrm{NMC}$ over 2 passages followed by 2 passages without exposure, (f) $25 \mathrm{mg} \mathrm{L}^{-1} \mathrm{NMC}$ ion eq. over 2 passages followed by 2 passages without exposure. Table indicates mean, median, and standard deviation in $\mu \mathrm{m}$ for the imaged microbe populations. Statistical analyses to compare the lengths of the bacteria are included in the ESI (Fig. S12). $\uparrow$ 
a

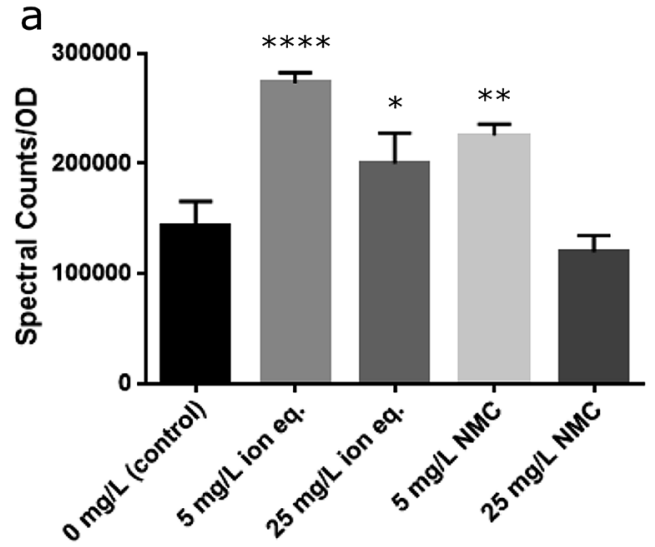

b

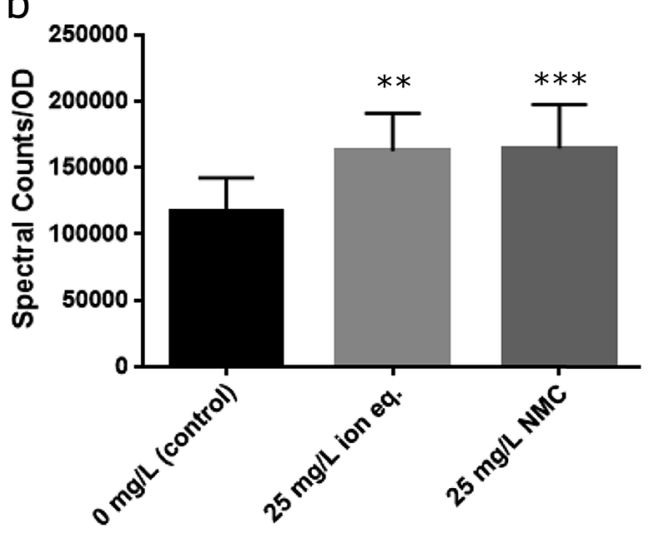

Fig. 8 Riboflavin secretion as measured with LC-MS. (a) Passage A demonstrates significant differences between the treated groups and the control. (b) Over multiple subsequent passages (average of B-E), the control differs from the ion- and NMC-treated samples, but these samples do not differ from one another. Statistical analysis performed with non-parametric one-way ANOVA with Tukey analysis as necessary $(\alpha=0.05$; $* * * * p \leq 0.0001 ; * * * p \leq 0.001 ; * * p \leq 0.01, * p \leq 0.05)$.

not increase when the population is exposed to triple the quantity of NMC (Fig. S14†). Although riboflavin is associated with the ability of $S$. oneidensis MR-1 to reduce metals extracellularly under anaerobic growth, the increased concentration may also indicate some metal related-utility under aerobic respiration.

Finally, we have also confirmed that there is no secreted factor, such as a protein or small molecule, which is responsible for the ability of the organism to survive exposure. Bacteria from the control population were cultured using spent media from NMC-adapted cultures. These cultures rebounded after exposure to $5 \mathrm{mg} \mathrm{L}^{-1}$ as seen previously, but did not grow in cultures containing $10 \mathrm{mg} \mathrm{L}^{-1}$ (Fig. S15 $\dagger$ ). These data provide further evidence that the adaptation is heritable, and not triggered by media factors or secreted biomolecules.

\section{Summary \& conclusions}

Nanoparticles have been considered a potential alternative to existing antibiotic treatments. Because they typically trigger multiple mechanisms of response, it has been postulated that bacteria may not develop resistance to nanoparticles. ${ }^{\mathbf{1 8 , 6 4 - 6 6}}$ Yet, bacteria and other microorganisms have always existed in environments that naturally contain metals, so it is not surprising that they can also adapt to the presence of metal nanoparticles. ${ }^{63}$ Here, we provide the first example of stable bacterial resistance to a metal nanoparticle, outside of antimicrobial silver materials, which were only recently demonstrated to spur resistance. ${ }^{38}$ Other studies investigating nanoparticle adaptations have shown clear bacterial response but have not demonstrated a stable nanoparticle resistance phenotype ${ }^{41,48,66-69}$ Due to the ability of $S$. oneidensis MR-1 to continue replication under increasing concentrations of NMC, the heritability and stability of the adaptation after the pressure has been removed, and the presence of a nanoparticle-specific impact, it is rational to consider this resistance and not simply tolerance. ${ }^{37,38,49,65}$
Microbial resistance is important to consider when addressing the regulation of soluble nanomaterials. There is a "particle-chemical duality challenge" that cannot be addressed when only assessing particle dissolution, especially when considering potential toxicity. ${ }^{70}$ Even for nanoparticles like NMC, where metal dissolution is responsible for much of the particle toxicity, there are toxic properties unique to the particle, which have also been reported for AgNPs. ${ }^{71}$ Other research has shown differential toxicity between a nanomaterial and its ions, but the ions were more toxic than the nanoparticle. ${ }^{38,72,73}$ In this work, we saw that ions were similarly toxic to the nanomaterial, but with further culturing and adaptation development, it was possible to distinguish between the toxicity of NMC and its equivalent ions by characterizing the adapted populations. There are several mechanisms of metal resistance that a bacteria may employ to mitigate NMC toxicity, but with multiple metals and an undetermined "nanoparticle-specific factor," elucidation of these mechanism will likely be complex. ${ }^{63}$ Future studies will work to determine the mechanisms of resistance and more thoroughly map the variations between ion and nanoparticle adaptation, as well as determine if nanoparticle resistance is possible in other organisms.

In sum, the presented studies make clear that it is critical to perform chronic exposure experiments when assessing the toxicity of nanomaterials as this is more similar to their environmental and medical mode of action. ${ }^{64}$ Such experiments enable the elucidation of permanent adaptation mechanisms, as seen here, and indicate that while many previously postulated that nanoparticles were unlikely to promote bacterial resistance due to their multiple mechanisms of action, these small organisms are readily able to adapt to such assaults. Given the essential roles that bacteria play in our ecosystems, it is clear that careful assessment of chronic exposure to engineered materials is required to avoid drastic modifications and unnecessary resistance in regions of contamination..$^{36,74-76}$ 


\section{Materials and methods}

The experimental flow chart across passages can be found in the ESI (Fig. S3). $\dagger$

\section{NMC synthesis and characterization}

Lithium nickel manganese cobalt oxide nanosheets with stoichiometric Ni : Mn : Co were synthesized as previously published. ${ }^{12}$ First, a nickel manganese cobalt hydroxide precursor with stoichiometric $\mathrm{Ni}$ : Mn was synthesized through dropwise addition of aqueous transition metal salt containing $0.2 \mathrm{M}$ nickel(II) acetate, $0.2 \mathrm{M}$ manganese(II) acetate, and 0.2 cobalt(II) acetate into $0.1 \mathrm{M}$ aqueous $\mathrm{LiOH}$ with stirring. The precursor was purified and isolated with multiple cycles of centrifugation with water $(2 \times)$ and methanol $(3 \times)$ before drying under a flow of nitrogen. The mixed metal hydroxide $(0.250 \mathrm{~g})$ was added to $10 \mathrm{~g}$ mixture of molten lithium salt flux (6:4 molar ratio of $\mathrm{LiNO}_{3}$ : $\mathrm{LiOH}$ ) at $205{ }^{\circ} \mathrm{C}$ for $30 \mathrm{~min}$ with stirring. The reaction is quenched with water to yield NMC nanosheets, which were purified with cycles of centrifugation $(2 \times$ water, $3 \times$ methanol $)$ and dried under a continuous flow of nitrogen. As described in previous studies, TEM images show sheet-like morphologies that average $\sim 80 \mathrm{~nm}$ across and the colloidal stability and aggregation of the particles were assessed by $\zeta$-potential and DLS (method fully detailed in the ESI $\dagger$ ). ${ }^{\mathbf{1 2 , 1 4}}$

To characterize metal dissolution into the bacteria media, a suspension of NMC was added to media to yield a final concentration of $5 \mathrm{mg} \mathrm{L}^{-1}$ and $25 \mathrm{mg} \mathrm{L}^{-1} \mathrm{NMC}$. Samples were agitated by an incubator shaker for $96 \mathrm{~h}$ at $30{ }^{\circ} \mathrm{C}$. Samples were collected in triplicate and centrifuged at $4696 \mathrm{~g}$ for $20 \mathrm{~min}$ to remove a majority of NMC in solution. The supernatant was again centrifuged to collect any remaining nanoparticles at $288000 \mathrm{~g}$ for $2 \mathrm{~h}$ using a Beckman Coulter Optima Ultracentrifuge with a SW-41 Ti Rotor. Resulting supernatants were measured by ICP-OES in triplicate to determine the concentration of dissolve metal species.

\section{Bacterial cultivation}

Shewanella oneidensis MR-1 (ATCC BAA1096) were grown on lysogeny broth (LB) agar plates at $30^{\circ} \mathrm{C}$ for $16 \mathrm{~h}$ and transferred in a minimal medium containing $11.6 \mathrm{mM} \mathrm{NaCl}, 4.0 \mathrm{mM} \mathrm{KCl}$, $1.4 \mathrm{mM} \mathrm{MgCl} 2,2.8 \mathrm{mM} \mathrm{Na}_{2} \mathrm{SO}_{4}, 2.8 \mathrm{mM} \mathrm{NH} \mathrm{NH}_{4} \mathrm{Cl} 88.1 \mu \mathrm{M}$ $\mathrm{Na}_{2} \mathrm{HPO}_{4}, 50.5 \mu \mathrm{M} \mathrm{CaCl}_{2}, 10 \mathrm{mM}$ HEPES, and $100 \mathrm{mM}$ fresh sodium lactate. Liquid cultures were grown at $30{ }^{\circ} \mathrm{C}$, shaking at $250 \mathrm{RPM}$, for $24 \mathrm{~h}$ into exponential phase. The cultures were diluted to an optical density (OD) of $\sim 0.2$ at $600 \mathrm{~nm}$ (GENESYS 20 spectrophotometer, ThermoFisher Scientific).

\section{Bacterial exposure cultivation and analysis}

Bacteria suspensions were diluted $1: 10 \mathrm{v} / \mathrm{v}$ into fresh media. NMC nanoparticle $\left(2 \mathrm{mg} \mathrm{mL}^{-1}\right)$ were dispersed in minimal media with sonication for $10 \mathrm{~min}$ and added to the cultures to attain the desired NMC concentration either at the time of the culture dilution (time $0 \mathrm{~h}$ ) or $10 \mathrm{~h}$ after dilution (time $10 \mathrm{~h}$ ). Likewise, stock solutions of $\mathrm{LiOH}, \mathrm{NiCl}_{2}, \mathrm{MnSO}_{4}$, and $\mathrm{CoCl}_{2}$ in minimal media were all added to the cultures at time 0 to achieve $\mathrm{Li}^{+}, \mathrm{Ni}^{2+}, \mathrm{Mn}^{2+}$, and $\mathrm{Co}^{2+}$ concentrations in the media according to the expected metal ion dissolution of NMC over $96 \mathrm{~h}$ as determined by ICP-OES (vide supra). All conditions were performed in triplicate. Bacterial growth was monitored by turbidity through optical absorbance at $600 \mathrm{~nm}$ every few $\mathrm{h}$ for 72-96 h (referred to as Passage A). A blank of minimal media with the same concentration of NMC was used.

For each subsequent exposure, the bacterial suspensions were diluted to an $\mathrm{OD}_{600}$ of 0.1 using minimal media without lactate and diluted 1:10 (v/v) into fresh media and lactate supplemented with NMC nanoparticle or metal ions at time 0 (Passages B-E). Carry-over of NMC or metal ions into subsequent cultures was considered negligible since the suspensions were diluted 20-30 times when in subsequent culture. After $96 \mathrm{~h}$, an aliquot from each culture from Passages A-E was collected for riboflavin analysis (vide infra).

\section{Respirometry experiments}

Passage E was used for respirometry experiments. Bacterial respiration, as a measure of bacteria fitness during exposure to NMC or metal ions, was determined by quantifying $\mathrm{O}_{2}(\mathrm{~g})$ consumption using a 24-vessel respirometer system (Respirometry Systems and Applications, Inc., Springdale, AR). Bacteria from Passage $\mathrm{D}$ were diluted to create a $100 \mathrm{~mL}$ suspension with a final $\mathrm{OD}_{600}$ of 0.01 for Passage E growth. Cultures were placed in a $125 \mathrm{~mL}$ glass vessel and supplemented with NMC and metal ions. The vessels were placed in a $30{ }^{\circ} \mathrm{C}$ water bath for $72 \mathrm{~h}$ with constant stirring (500 rpm) and under constant $\mathrm{O}_{2}$ pressure. The $\mathrm{CO}_{2}$ produced by the respiring bacteria was scrubbed with a $\mathrm{KOH}$ insert in the headspace of the vessel. As $\mathrm{CO}_{2}$ was removed from the gas phase, $\mathrm{O}_{2}$ was delivered to the vessel every $5 \mathrm{~min}$ to maintain a constant pressure. The total mass of $\mathrm{O}_{2}$ delivered to the system and the time it took to reach the highest rate of respiration (as determined by the first derivative of the respiration curve) were used as a measure of bacterial fitness and metabolic activity.

\section{Riboflavin analysis}

Aliquots of cultures from Passages A-E were collected at the end of each growth curve and centrifuged to remove bacteria $(3220 \mathrm{~g}$, $10 \mathrm{~min})$. Supernatants ( $2 \mu \mathrm{L}$ injected) were analyzed on an UHD Accurate-Mass Q-TOF LC/MS instrument (Agilent, 6540), separated on a reverse phase $\mathrm{C}_{18}$ column (Agilent, Eclipse Plus, $2.1 \times$ $50 \mathrm{~mm}, 1.8 \mu \mathrm{m}$ ), and detected by electrospray ionization (positive ion mode). Sample were separation was initiated with an isocratic elution of $100 \% \mathrm{~A}$ at $0.40 \mathrm{~mL} \mathrm{~min}^{-1}$ for $2 \mathrm{~min}$ followed by a linear gradient of $0-100 \% \mathrm{~B}$ over $7 \mathrm{~min}$, then an isocratic elution at $100 \%$ B for $1 \mathrm{~min}$ (A: $95: 5 \mathrm{H}_{2} \mathrm{O}: \mathrm{ACN}, 0.1 \%$ formic acid; B: 95 : 5 ACN : $\mathrm{H}_{2} \mathrm{O}, 0.1 \%$ formic acid).

\section{Bacteria morphology analysis with electron microscopy}

All SEM samples from Passage D were prepared by pelleting from growth media and washing with $1 \times$ DPBS $(10 \mathrm{~mL}, 750 g)$, followed by a wash with $2 \mathrm{mM}$ HEPES buffer $(10 \mathrm{~mL}, 750 g)$. Samples were then fixated with $5 \%$ glutaraldehyde $(500 \mu \mathrm{L})$, 
with an incubation of $30 \mathrm{~min}$, followed by two washes of $0.1 \mathrm{M}$ phosphate buffer $(500 \mu \mathrm{L}, 1200 g)$. Cells underwent dehydration by ethanol in successive steps of increase ethanol concentrations $(35 \%, 50 \%, 75 \%, 95 \%, 100 \% ; 500 \mu \mathrm{L}, 1200 g)$. Final dehydration occurred by two washes with HDMS $(500 \mu \mathrm{L}, 800 g)$. Cells from the second HDMS wash were allowed to desiccate directly onto glass cover slides. Sample slides were sputter coated with a thin layer of gold to increase conductivity just before being placed into the SEM for imaging. Samples were imaged on a JEOL JSM-IT100 SEM at a working distance of $10 \mathrm{~mm}$ with a probe current of $0.045 \mu \mathrm{A}$ and electron gun voltage of $5 \mathrm{kV}$.

\section{Analysis of SEM images}

Dimensions of Passage D bacteria analyzed were blinded in SEM preparation and analysis in ImageJ. Using ImageJ, each cell's width and length was measured, after the image was calibrated using the scale bar. The cell length was measured by using the segmented line tool down the center of the bacteria. The width was measured with the straight line tool on a portion of the bacteria where the cell membrane was intact and not curving. A cell was only measured if its start and end was clearly defined. The growth conditions of each sample were double blinded before the bacteria were measured.

\section{Conflicts of interest}

There are no conflicts to declare.

\section{Acknowledgements}

This work was supported by the National Science Foundation under the Center for Sustainable Nanotechnology, CHE1503408. The Center for Sustainable Nanotechnology is part of the Centers for Chemical Innovation Program. S. Mitchell acknowledges support through a NIH Chemistry-Biology Interface Training Grant 5T32GM008700-18. N. Hudson-Smith acknowledges support through the National Science Foundation Graduate Research Fellowship Program (00039202). Parts of this work were carried out in the Characterization Facility, University of Minnesota, which receives partial support from NSF through the MRSEC program. The authors gratefully acknowledge use of shared transmission electron microscopy instrumentation in the UW Madison Materials Science Center, which is partially supported by NSF through the University of Wisconsin Materials Research Science and Engineering Center (DMR-1720415). We thank J. Buchman for helpful discussion.

\section{References}

1 T. M. Benn and P. Westerhoff, Nanoparticle Silver Released into Water from Commercially Available Sock Fabrics, Environ. Sci. Technol., 2008, 42, 4133-4139.

2 R. S. Lankone, K. E. Challis, Y. Bi, D. Hanigan, R. B. Reed, T. Zaikova, J. E. Hutchison, P. Westerhoff, J. Ranville, H. Fairbrother and L. M. Gilbertson, Methodology for
Quantifying Engineered Nanomaterial Release from Diverse Product Matrices under Outdoor Weathering Conditions and Implications for Life Cycle Assessment, Environ. Sci.: Nano, 2017, 4, 1784-1797.

3 D. V. Talapin and J. Steckel, Quantum Dot Light-Emitting Devices, MRS Bull., 2013, 38, 685-691.

4 M. Stefaniuk, P. Oleszczuk and Y. S. Ok, Review on Nano Zerovalent Iron (nZVI): From Synthesis to Environmental Applications, Chem. Eng. J., 2016, 287, 618-632.

5 J. R. Morones-Ramirez, J. A. Winkler, C. S. Spina and J. J. Collins, Silver Enhances Antibiotic Activity against Gram-Negative Bacteria, Sci. Transl. Med., 2013, 5, 190 ra181.

6 G. Franci, A. Falanga, S. Galdiero, L. Palomba, M. Rai, G. Morelli and M. Galdiero, Silver Nanoparticles as Potential Antibacterial Agents, Molecules, 2015, 20, 88568874.

7 Y. Xie, Y. He, P. L. Irwin, T. Jin and X. Shi, Antibacterial Activity and Mechanism of Action of Zinc Oxide Nanoparticles against Campylobacter jejuni, Appl. Environ. Microbiol., 2011, 77, 2325-2331.

8 M. Hans, A. Erbe, S. Mathews, Y. Chen, M. Solioz and F. Mücklich, Role of Copper Oxides in Contact Killing of Bacteria, Langmuir, 2013, 29, 16160-16166.

9 D. M. Aruquete, B. Kim, M. F. Hochella, Y. Ma, Y. Cheng, A. Hoegh, J. Liu and A. Pruden, Antimicrobial Nanotechnology: Its Potential for the Effective Management of Microbial Drug Resistance and Implications for Research Needs in Microbial Nanotoxicology, Environ. Sci.: Processes Impacts, 2013, 15, 93-102.

10 G. A. Sotiriou and S. E. Pratsinis, Antibacterial Activity of Nanosilver Ions and Particles, Environ. Sci. Technol., 2010, 44, 5649-5654.

11 A. Sirelkhatim, S. Mahmud, A. Seeni, N. H. M. Kaus, L. C. Ann, S. K. M. Bakhori, H. Hasan and D. Mohamad, Review on Zinc Oxide Nanoparticles: Antibacterial Activity and Toxicity Mechanism, Nano-Micro Lett., 2015, 7, 219-242.

12 M. N. Hang, I. L. Gunsolus, H. Wayland, E. S. Melby, A. C. Mensch, K. R. Hurley, J. A. Pedersen, C. L. Haynes and R. J. Hamers, Impact of Nanoscale Lithium Nickel Manganese Cobalt Oxide (NMC) on the Bacterium Shewanella oneidensis MR-1, Chem. Mater., 2016, 28, 10921100.

13 C. Gunawan, W. Y. Teoh, C. P. Marquis and R. Amal, Cytotoxic Origin of Copper (II) Oxide Nanoparticles: Comparative Studies with Micron-Sized Particles, Leachate, and Metal Salts, ACS Nano, 2011, 5, 7214-7225.

14 I. L. Gunsolus, M. N. Hang, N. V. Hudson-Smith, J. T. Buchman, J. W. Bennett, D. Conroy, S. E. Mason, R. J. Hamers and C. L. Haynes, Influence of Nickel Manganese Cobalt Oxide Nanoparticle Composition on Toxicity toward Shewanella oneidensis MR-1: Redesigning for Reduced Biological Impact, Environ. Sci.: Nano, 2017, 4, 636-646.

15 M. Auffan, W. Achouak, J. Rose, M.-A. Ronacato, C. Chanéac, D. T. Waite, A. Masion, J. C. Woicik, M. R. Wiesner and J.-Y. Bottero, Relation between the Redox State and Iron- 
Based Nanoparticles and Their Cytotoxicity toward Escherichia coli, Environ. Sci. Technol., 2008, 42, 6730-6735.

16 M. R. Hartono, A. Kushmaro, X. Chen and R. S. Marks, Probing the Toxicity Mechanism of Multiwalled Carbon Nanotubes on Bacteria, Environ. Sci. Pollut. Res. Int., 2017, 25, 5003-5012.

17 S. Mahendra, H. Zhu, V. L. Colvin and P. J. Alvarez, Quantum Dot Weathering Results in Microbial Toxicity, Environ. Sci. Technol., 2008, 42, 9424-9430.

18 L. Wang, C. Hu and L. Shao, The Antimicrobial Activity of Nanoparticles: Present Situation and Prospects for the Future, Int. J. Nanomed., 2017, 12, 1227-1249.

19 E. A. Olivetti, G. Ceder, G. G. Gaustad and X. Fu, Lithium-Ion Battery Supply Chain Considerations: Analysis of Potential Bottlenecks in Critical Metals, Joule, 2017, 1, 229-243.

20 P. Patel, Improving the Lithium-Ion Battery, ACS Cent. Sci., 2015, 1, 161-162.

21 J. F. Heidelberg, I. T. Paulsen, K. E. Nelson, E. J. Gaidos, W. C. Nelson, T. D. Read, J. A. Eisen, R. Seshadri, N. Ward, B. Methe, R. A. Clayton, T. Meyer, A. Tsapin, J. Scott, M. Beanan, L. Brinkac, S. Daugherty, R. T. DeBoy, R. J. Dodson, A. S. Durkin, et al., Genome Sequence of the Dissimilatory Metal Ion-Reducing Bacterium Shewanella oneidensis, Nat. Biotechnol., 2002, 20, 1118-1123.

22 A. S. Beliaev, D. M. Klingeman, J. A. Klappenbach, L. Wu, M. F. Romine, J. M. Tiedje, K. H. Nealson, J. K. Fredrickson and J. Zhou, Global Transcriptome Analysis of Shewanella oneidensis MR-1 Exposed to Different Terminal Electron Acceptors, J. Bacteriol., 2005, 187, 7138-7145.

23 B. B. Li, Y. Y. Cheng, Y. Y. Fan, D. F. Liu, C. Y. Fang, C. Wu, W. W. Li, Z. C. Yang and H. Q. Yu, Estimates of Abundance and Diversity of Shewanella Genus in Natural and Engineered Aqueous Environments with Newly Designed Primers, Sci. Total Environ., 2018, 637-638, 926-933.

24 S. L. Brauer, C. Adams, K. Kranzler, D. Murphy, M. Xu, P. Zuber, H. M. Simon, A. M. Baptista and B. M. Tebo, Culturable Rhodobacter and Shewanella Species Are Abundant in Estuarine Turbidity Maxima of the Columbia River, Environ. Microbiol., 2011, 13, 589-603.

25 J. Wang, J. Fang, L. Wei, Y. Zhang, H. Deng, Y. Guo, C. Hu and Y. Meng, Decrease of Microbial Community Diversity, Biogenic Amines Formation, and Lipid Oxidation by Phloretin in Atlantic Salmon Fillets, LWT, 2019, 101, 419426.

26 Y. Y. Fan, B. B. Li, Z. C. Yang, Y. Y. Cheng, D. F. Liu and H. Q. Yu, Abundance and Diversity of Iron Reducing Bacteria Communities in the Sediments of a Heavily Polluted Freshwater Lake, Appl. Microbiol. Biotechnol., 2018, 102, 10791-10801.

27 E. F. Pane, J. C. McGreer and C. M. Wood, Effects of Chronic Waterborne Nickel Exposure on Two Successive Generations of Daphnia magna, Environ. Toxicol. Chem., 2004, 23, 10511056.

28 C. Roose-Amsaleg, C. Yan, A.-M. Hoang and A. M. Laverman, Chronic Exposure of River Sediments to Environmentally Relevant Levels of Tetracycline Affects Bacterial
Communities but Not Denitrification Rates, Ecotoxicology, 2013, 22, 1467-1478.

29 E. Wistrand-Yuen, M. Knopp, K. Hjort, S. Koskiniemi, O. G. Berg and D. I. Andersson, Evolution of High-Level Resistance During Low-Level Antibiotic Exposure, Nat. Commun., 2018, 9, 1599.

30 I. Brook, Inoculum Effect, Rev. Infect. Dis., 1989, 11, 361-368. 31 S. Viamajala, B. M. Peyton, R. K. Sani, W. A. Apel and J. D. Peterson, Toxic Effects of Chromium(vi) on Anaerobic and Aerobic Growth of Shewanella oneidensis MR-1, Biotechnol. Prog., 2004, 20, 87-95.

32 F. Faghihzadeh, N. M. Anaya, C. Astudillo-Castro and V. Oyanedel-Craver, Kinetic, Metabolic and Macromolecular Response of Bacteria to Chronic Nanoparticle Exposure in Continuous Culture, Environ. Sci.: Nano, 2018, 5, 1386-1396.

33 M. Gault, G. Effantin and A. Rodrigue, Ni Exposure Impacts the Pool of Free Fe and Modifies DNA Supercoiling via MetalInduced Oxidative Stress in Escherichia coli $\mathrm{K}-12$, Free Radical Biol. Med., 2016, 97, 351-361.

34 F. Barras and M. Fontecave, Cobalt Stress in Escherichia coli and Salmonella enterica: Molecular Bases for Toxicity and Resistance, Metallomics, 2011, 3, 1130-1134.

35 L. Macomber and R. P. Hausinger, Mechanisms of Nickel Toxicity in Microorganisms, Metallomics, 2011, 3, 11531162.

36 C. Gunawan, W. Y. Teoh, C. P. Marquis and R. Amal, Induced Adaptation of Bacillus sp. To Antimicrobial Nanosilver, Small, 2013, 9, 3554-3560.

37 J. L. Graves, M. Tajkarimi, Q. Cunningham, A. Campbell, H. Nonga, S. H. Harrison and J. E. Barrick, Rapid Evolution of Silver Nanoparticle Resistance in Escherichia coli, Front. Genet., 2015, 6, 42.

38 A. Panáček, L. Kvítek, M. Smékalová, R. Večeřová, M. Kolář, M. Röderová, F. Dyčka, M. Šebela, R. Prucek, O. Tomanec and R. Zbořil, Bacterial Resistance to Silver Nanoparticles and How to Overcome It, Nat. Nanotechnol., 2018, 13, 65-71.

39 A. Ivask, A. ElBadawy, C. Kaweeteerawak, D. Boren, H. Fischer, Z. Ji, C. H. Chang, R. Liu, T. Tolaymat, D. Telesca, J. I. Zink, Y. Cohen, P. A. Holden and H. A. Godwin, Toxicity Mechanisms in Escherichia coli Vary for Silver Nanoparticles and Differ from Ionic Silver, ACS Nano, 2014, 8, 374-386.

40 C. Kaweeteerawak, C. H. Chang, K. R. Roy, R. Liu, R. Li, D. Toso, H. Fischer, A. Ivask, Z. Ji, J. I. Zink, Z. H. Zhou, G. F. Chanfreau, D. Telesca, Y. Cohen, P. A. Holden, A. E. Nel and H. A. Godwin, $\mathrm{Cu}$ Nanoparticles Have Different Impacts in Escherichia coli and Lactobacillus brevis Than Their Microsized and Ionic Analogues, ACS Nano, 2015, 9, 7215-7225.

41 Y. Zhang, A. Z. Gu, S. Xie, X. Li, T. Cen, D. Li and J. Chen, Nano-Metal Oxides Induce Antimicrobial Resistance via Radical-Mediated Mutagenesis, Environ. Int., 2018, 121, 1162-1171.

42 H. H. Lara, N. V. Ayala-Núñez, L. C. I. Turrent and C. R. Padilla, Bactericidal Effect of Silver Nanoparticles 
against Multidrug-Resistant Bacteria, World J. Microbiol. Biotechnol., 2009, 26, 615-621.

43 J. P. Schimel, T. C. Balser and M. Wallenstein, Microbial Stress-Response Physiology and Its Implications for Ecosystem Function, Ecology, 2007, 88, 1386-1394.

44 B. Glasl, N. S. Webster and D. G. Bourne, Microbial Indicators as a Diagnostic Tool for Assessing Water Quality and Climate Stress in Coral Reef Ecosystems, Mar. Biol., 2017, 164, 91.

45 B. Li, Y. Qiu, H. Shi and H. Yin, The Importance of Lag Time Extension in Determining Bacterial Resistance to Antibiotics, Analyst, 2016, 141, 3059-3067.

46 M. C. Santimano and M. Kowshik, Altered Growth and Enzyme Expression Profile of ZnO Nanoparticles Exposed Non-Target Environmentally Beneficial Bacteria, Environ. Monit. Assess., 2013, 185, 7205-7214.

47 L. Gabrielyan, L. Hakobyan, A. Hovhannisyan and A. Trchounian, Effects of Iron Oxide $\left(\mathrm{Fe}_{3} \mathrm{O}_{4}\right)$ Nanoparticles on Escherichia coli Antibiotic-Resistant Strains, J. Appl. Microbiol., 2019, 126, 1108-1116.

48 S. P. Dhas, P. J. Shiny, S. Khan, A. Mukherjee and N. Chandrasekaran, Toxic Behavior of Silver and Zinc Oxide Nanoparticles on Environmental Microorganisms, $J$. Basic Microbiol., 2014, 54, 916-927.

49 A. Brauner, O. Fridman, O. Gefen and N. Q. Balaban, Distinguishing between Resistance, Tolerance and Persistence to Antibiotic Treatment, Nat. Rev. Microbiol., 2016, 14, 320-330.

50 S. S. Justice, D. A. Hunstad, L. Cegelsk and S. J. Hultgren, Morphological Plasticity as a Bacterial Survival Strategy, Nat. Rev. Microbiol., 2008, 6, 162-168.

51 M. C. F. van Teeseling, M. A. de Pedro and F. Cava, Determinants of Bacterial Morphology: From Fundamentals to Possibilities for Antimicrobial Targeting, Front. Microbiol., 2017, 8, 1264.

52 K. Chourey, M. R. Thompson, J. Morrell-Falvey, N. C. VerBerkmoes, S. D. Brown, M. Shah, J. Zhou, M. Doktycz, R. L. Hettich and D. K. Thompson, Global Molecular and Morphological Effects of 24-Hour Chromium(vi) Exposure on Shewanella oneidensis M-1, Appl. Environ. Microbiol., 2006, 72, 6331-6344.

53 S. Pramanik, S. K. E. Hill, B. Zhi, N. V. Hudson-Smith, J. J. Wu, J. N. White, E. A. McIntire, V. S. S. K. Kondeti, A. L. Lee, P. J. Bruggeman, U. R. Kortshagen and C. L. Haynes, Comparative Toxicity Assessment of Novel Si Quantum Dots and Their Traditional Cd-Based Counterparts Using Bacteria Models Shewanella oneidensis and Bacillus subtilis, Environ. Sci.: Nano, 2018, 5, 1890-1901.

54 Y.-M. Zhang and C. O. Rock, Membrane Lipid Homeostasis in Bacteria, Nat. Rev. Microbiol., 2008, 6, 222-233.

55 Y. G. Yuan, Q. L. Peng and S. Gurunathan, Effects of Silver Nanoparticles on Multiple Drug-Resistant Strains of Staphylococcus aureus and Pseudomonas aeruginosa from Mastitis-Infected Goats: An Alternative Approach for Antimicrobial Therapy, Int. J. Mol. Sci., 2017, 18, E569.

56 Z. V. Feng, I. L. Gunsolus, T. A. Qiu, K. R. Hurley, L. H. Nyberg, H. Frew, K. P. Johnson, A. M. Vartanian,
L. M. Jacob, S. E. Lohse, M. D. Torelli, R. J. Hamers, C. J. Murphy and C. L. Haynes, Impacts of Gold Nanoparticle Charge and Ligand Type on Surface Binding and Toxicity to Gram-Negative and Gram-Positive Bacteria, Chem. Sci., 2015, 6, 5186-5196.

57 S. Murínová and K. Dercová, Response Mechanisms of Bacterial Degraders to Environmental Contaminants on the Level of Cell Walls and Cytoplasmic Membrane, Int. J. Microbiol., 2014, 2014, 873081.

58 N. J. Kotloski and J. A. Gralnick, Flavin Electron Shuttles Dominate Extracellular Electron Transfer by Shewanella oneidensis, mBio, 2013, 4, e00553-12.

59 M. Fischer and A. Bacher, Biosynthesis of Vitamin $B_{2}$ : Structure and Mechanism of Riboflavin Synthase, Arch. Biochem. Biophys., 2008, 474, 252-265.

60 H. H. Hau, A. Gilbert, D. Coursolle and J. A. Gralnick, Mechanism and Consequences of Anaerobic Respiration of Cobalt by Shewanella oneidensis Strain MR-1, Appl. Environ. Microbiol., 2008, 74, 6880-6886.

61 D. Coursolle, D. B. Baron, D. R. Bond and J. A. Gralnick, The Mtr Respiratory Pathway Is Essential for Reducing Flavins and Electrodes in Shewanella oneidensis, J. Bacteriol., 2010, 192, 467-474.

62 M. A. Maurer-Jones, I. L. Gunsolus, B. M. Meyer, C. J. Christenson and C. L. Haynes, Impact of $\mathrm{TiO}_{2}$ Nanoparticles on Growth, Biofilm Formation, and Flavin Secretion in Shewanella oneidensis, Anal. Chem., 2013, 85, 5810-5818.

63 M. R. Bruins, S. Kapil and F. W. Oehme, Microbial Resistance to Metals in the Environment, Ecotoxicol. Environ. Saf., 2000, 45, 198-207.

64 C. S. Yah and G. S. Simate, Nanoparticles as Potential New Generation Broad Spectrum Antimicrobial Agents, Daru, J. Pharm. Sci., 2015, 23, 43.

65 A. Panáček, M. Smékalová, R. Večeřová, K. Bogdanová, M. Röderová, M. Kolář, M. Kilianová, S. Hradilová, J. P. Froning, M. Havrdová, R. Prucek, R. Zbořil and L. Kvítek, Silver Nanoparticles Strongly Enhance and Restore Bactericidal Activity of Inactive Antibiotics against Multiresistant Enterobacteriaceae, Colloids Surf., B, 2016, 142, 392-399.

66 R. Zhang, F. Carlsson, M. Edman, M. Hummelgård, B.-G. Jonsson, D. Bylund and H. Olin, Escherichia Coli Bacteria Develop Adaptive Resistance to Antibacterial ZnO Nanoparticles, Adv. Biosyst., 2018, 2, 1800019.

67 D. Mu, X. Yu, Z. Xu, Z. Du and G. Chen, Physiological and Transcriptomic Analyses Reveal Mechanistic Insight into the Adaption of Marine Bacillus subtilis C01 to Alumina Nanoparticles, Sci. Rep., 2016, 6, 29953.

68 P. Kotchaplai, E. Khan and A. S. Vangnai, Membrane Alterations in Pseudomonas putida F1 Exposed to Nanoscale Zerovalent Iron: Effects of Short-Term and Repetitive nZVI Exposure, Environ. Sci. Technol., 2017, 51, 7804-7813.

69 J. Ma, M. Kang, Y. Zhang, X. Guo, Z. Tian, C. Ding and H. Wang, Self-Defense of Escherichia coli against Damages Caused by Nanoalumina, Environ. Toxicol. Pharmacol., 2017, 55, 110-117. 
70 F. C. Klaessig, Dissolution as a Paradigm in Regulating Nanomaterials, Environ. Sci.: Nano, 2018, 5, 1070-1077.

71 L. M. Stabryla, K. A. Johnston, J. E. Millstone and L. M. Gilbertson, Emerging Investigator Series: It's Not All About the Ion: Support for Particle-Specific Contributions to Silver Nanoparticle Antimicrobial Activity, Environ. Sci.: Nano, 2018, 5, 2047-2068.

72 Y. Choi, H.-A. Kim, K.-W. Kim and B.-T. Lee, Comparative Toxicity of Silver Nanoparticles and Silver Ions to Escherichia coli, J. Environ. Sci., 2018, 66, 50-60.

73 N. Hachicho, P. Hoffmann, K. Ahlert and H. J. Heipieper, Effect of Silver Nanoparticles and Silver Ions on Growth and Adaptive Response Mechanisms of Pseudomonas putida mt-2, FEMS Microbiol. Lett., 2014, 355, 71-77.
74 Y. Ge, J. H. Priester, L. C. Van De Werfhorst, J. P. Schimel and P. A. Holden, Potential Mechanisms and Environmental Controls of $\mathrm{TiO}_{2}$ Nanoparticle Effects on Soil Bacterial Communities, Environ. Sci. Technol., 2013, 47, 14411-14417.

75 R. H. Stauber, S. Siemer, S. Becker, G.-B. Ding, S. Strieth and S. K. Knauer, Small Meets Smaller: Effects of Nanomaterials on Microbial Biology, Pathology, and Ecology, ACS Nano, 2018, 12, 6351-6359.

76 C. Gunawan, C. P. Marquis, R. Amal, G. A. Sotiriou, S. A. Rice and E. J. Harry, Widespread and Indiscriminate Nanosilver Use: Genuine Potential for Microbial Resistance, ACS Nano, 2017, 11, 3438-3445. 